\title{
Prospective study on severe malaria among in-patients at Bombo regional hospital, Tanga, north-eastern Tanzania
}

\author{
Hamisi A Msangeni*, Mathias L Kamugisha, Samuel H Sembuche, Ezekiel K Malecela, Juma A Akida, \\ Filbert F Temba, Bruno P Mmbando and Martha M Lemnge
}

\begin{abstract}
Background: In Tanzania, malaria is the major cause of morbidity and mortality, accounting for about 30\% of all hospital admissions and around 15\% of all hospital deaths. Severe anaemia and cerebral malaria are the two main causes of death due to malaria in Tanga, Tanzania.

Methods: This was a prospective observational hospital-based study conducted from October 2004 to September 2005. Consent was sought from study participants or guardians in the wards. Finger prick blood was collected from each individual for thick and thin smears, blood sugar levels and haemoglobin estimations by Haemocue machine after admission.

Results: A total of 494 patients were clinically diagnosed and admitted as cases of severe malaria. Majority of them (55.3\%) were children below the age of 5 years. Only 285 out of the total 494 (57.7\%) patients had positive blood smears for malaria parasites. Adults aged 20 years and above had the highest rate of cases with fever and blood smear negative for malaria parasites. Commonest clinical manifestations of severe malaria were cerebral malaria (47.3\%) and severe anaemia (14.6\%), particularly in the under-fives. Case fatality was 3.2\% and majority of the deaths occurred in the under-fives and adults aged 20 years and above with negative blood smears.

Conclusion: Proper laboratory diagnosis is crucial for case management and reliable data collection. The nonspecific nature of malaria symptomatologies limits the use of clinical diagnosis and the IMCI strategy.

Strengthening of laboratory investigations to guide case management is recommended.
\end{abstract}

\section{Background}

Malaria is the leading cause of morbidity and mortality affecting about 300-400 million people worldwide and accounts for about 1-2 million deaths every year. It is also the most prevalent tropical disease especially in subSaharan Africa [1,2]. Major causes of malaria related deaths are severe anaemia and cerebral malaria [3-8]. According to Annual report from Bombo regional hospital for the year 2000, clinically diagnosed malaria accounted for $59.9 \%$ of all admissions of which $21.6 \%$ had had the severe form of the disease. Anaemia contributed $18.6 \%$ of all admissions. There were 228 deaths reported in the paediatric ward of which $33.3 \%$ were due to anaemia that was

\footnotetext{
* Correspondence: hmsangeni@yahoo.co.uk
National Institute for Medical Research, Tanga Medical Research Centre, P.O.

* Correspondence: hmsangeni@yahoo.co.uk
National Institute for Medical Research, Tanga Medical Research Centre, P.O. Box 5004, Tanga, Tanzania
}

most likely caused by malaria. Causes of severe malaria other than anaemia accounted for $30.7 \%$ of all reported deaths [9].

Due to their low acquired immune status, children below five years of age are the most affected by malaria in high transmission areas, whereas in low transmission areas all age groups are equally affected $[10,11]$. Although health facility-based reports show that malaria is the leading cause for hospital attendance and admissions, several studies across Africa indicate that the disease is declining [12-14]. This has also been found in two recently conducted studies at one health facility in the city of Tanga (Makorora Health Centre), where only $10 \%$ of patients screened in one study were positive for malaria parasites [15], and in the other study (Msangeni et al, unpublished) data collection activities had to be 
stopped after failure to obtain suitable candidates despite most of the patients having clinical symptoms suggestive of malaria.

Apart from these two studies which have shown very low malaria prevalence, there is still inadequate information on the epidemiology of laboratory confirmed malaria and the underlying associated risk factors. It was the objective of this study, therefore, to determine the malaria disease pattern and the proportion of malaria associated deaths in patients admitted at Bombo regional hospital. The study was conducted for a period of one year from October 2004 to September 2005 and involved prospective data collection from severe malaria cases admitted to Bombo hospital.

\section{Methods}

\section{Study area}

The study was conducted in the city of Tanga, at Bombo regional hospital, north-eastern Tanzania. The city lies at about $5.17^{\circ}, 5.33^{\circ} \mathrm{S}$ and $38.17^{\circ}, 38.33^{\circ} \mathrm{E}$ along the Indian Ocean seashore. The area receives two seasons of rainfall; short rains during the months of October - December and long rains in March - June, with a humidity of about $100 \%$. Temperature ranges between $27^{\circ} \mathrm{C}$ and $32^{\circ} \mathrm{C}$. Tanga city covers an area of about $600 \mathrm{sq} . \mathrm{km}$ and has an estimated human population of 248,696 (2003 estimated at a growth rate of $2.1 \%$ per annum). The hospital has a capacity of 500 beds for inpatients among which 60 beds are reserved for paediatric patients. It has a general laboratory for both in-patient and out-patient services.

Based on data from Bombo regional hospital for the year 2003, malaria was indicated as the leading cause of hospital admissions in the intensive care unit (ICU), medical and paediatric wards, accounting for $56.8 \%, 39.0 \%$ and $47.5 \%$ respectively. Severe anaemia and severe malaria were noted to be the leading cause of deaths in the paediatric ICU with rates of $61.5 \%$ and $45.8 \%$ respectively. Anaemia was most probably related to malaria, especially in children.

\section{Study design}

This was a prospective observational hospital based study conducted from 2004 to September 2005. Malaria case admissions and outcome were collected and analysed. The data were collected during official working hours and only on five working days of the week.

\section{Ethical consideration}

Study aims were explained to Bombo hospital management team in order to make them aware and get fully involved in the study execution. Permission to conduct the study in Bombo regional hospital was sought from the Regional and City administrative authorities. During all these meetings, study aims and activities were elaborated and clarified when necessary. Oral and written consents were sought from the study participants or guardians/caretakers in the wards. Consent for adult patients with cerebral involvement was sought through relatives/caretakers. Patients' data were taken as confidential entities. The study was granted ethical clearance by the Medical Research Co-ordinating Committee of the National Institute for Medical Research.

\section{Clinical and laboratory data collection}

Patients were admitted at the out-patient department (OPD), usually by clinical officers. The study group comprised of all patients admitted with a clinical diagnosis of severe malaria. Both sexes and all ages were eligible for inclusion in the study. Proposed diagnoses by the hospital staff were entered in the morbidity form as they were. Morbidity questionnaire was completed for all malaria admissions in the wards. Clinical reassessment and laboratory investigations were done in the ward by the research team. From each individual, personal data including name, sex, age, ward, village/street, as well as clinical and parasitological examination results were entered in the morbidity form. Clinical notes of every patient were reviewed on discharge to see if there was any re-evaluation and subsequent change of the initial diagnosis. Patients who had a change of diagnosis from malaria to another febrile illness on discharge were excluded from the study. Cerebral involvement was assessed using Blantyre coma score $[16,17]$ by investigators.

Finger prick blood was collected from each individual for thick and thin smears. For all cases, finger prick blood was also taken for $\mathrm{Hb}$ level and blood sugar examinations using Haemocue machine. The blood smears were stained using $10 \%$ Giemsa for 30 minutes and examined under the microscope for identification and enumeration of malaria parasites. Malaria parasites were counted against 200 leukocytes. A blood smear was considered negative if no malaria parasites were seen after scanning 200 high power fields. When sexual parasites were present, they were enumerated against 500 leukocytes. Hyperparasitaemia was defined as parasite density $\geq 250,000$ rings $/ \mu \mathrm{L}$ of blood [18]. Anaemia was defined as $\mathrm{Hb}<11 \mathrm{~g} / \mathrm{dL}[19,20]$. Severe anaemia was classified as $\mathrm{Hb}<5 \mathrm{~g} / \mathrm{dL}$ [21] whereas $\mathrm{Hb}$ between $5 \mathrm{~g} / \mathrm{dL}$ and $\mathrm{Hb}<$ $11 \mathrm{~g} / \mathrm{dL}$ was termed as mild/moderate anaemia $[8,22]$. Hypoglycaemia was defined as blood glucose $<2.2$ mmole/L or $<40 \mathrm{mg} / \mathrm{dL}[18,23]$. Fever was defined as body temperature $\geq 37.5^{\circ} \mathrm{C}$ and hyperpyrexia as temperature $\geq 39.5^{\circ} \mathrm{C}$ [18]. Severe malaria was reassessed according to WHO 2000 guidelines [18]. In adults, splenomegaly was defined as palpable spleen of any size but for children we considered splenomegaly when the size of the spleen exceeded $2 \mathrm{~cm}$ below the left costal margin. Spleen enlargement was scored according to Hackett's 
classification. Deaths which occurred during data collection period were also recorded.

\section{Treatment of severe cases in the hospital}

Initial assessment was done at the OPD on admission to ascertain the presence of any severe signs which would require special attention. Parenteral/oral paracetamol was prescribed as antipyretic and analgesic whereas parenteral diazepam was prescribed to patients presenting with convulsions. Blood transfusion was provided in the case of severe anaemia $(\mathrm{Hb}<5 \mathrm{~g} / \mathrm{dL})$ after screening for HIV, grouping and cross-matching of the blood. According to national policy quinine is the drug of choice. The drug is administered by loading and maintenance doses. There is a slight difference between the regimen for adults and for children. The loading dose for adults is $20 \mathrm{mg} / \mathrm{kg}$ body weight of quinine hydrochloride salt diluted in $10 \mathrm{ml} / \mathrm{kg}$ of $5 \%$ dextrose by intravenous infusion. The drip is left to run for over 4 hours. A maintenance dose of quinine follows 8 hours from the beginning of the previous (loading) dose and is given at $10 \mathrm{mg} / \mathrm{kg}$ in similar IV drip, again running over 4 hours. The maintenance dose is repeated every 8 hours, calculated from the beginning of the previous infusion, until patient improves to an extent that he can swallow. Then oral quinine (tablets), $10 \mathrm{mg}$ salt/ $\mathrm{kg}$, is given 8 hourly intervals to complete a 7 days treatment course. As for children, a loading dose of quinine is administered exactly like in adults $(20 \mathrm{mg} / \mathrm{kg})$, running over 4 hours, followed by a maintenance dose $(10 \mathrm{mg} / \mathrm{kg})$ 12 hours after the start of the loading dose, given over 2 hours. This maintenance dose is repeated every 12 hours, estimated from the beginning of the previous drip. When the patient improves and can swallow, the quinine dose is given orally, $10 \mathrm{mg} / \mathrm{kg} 8$ hourly to complete a 7 day treatment course.

\section{Data management and analysis}

Data collected from this study were handled using Epi-info software and were double entered to minimize errors during data entry process while check files were created to restrict entrance of invalid data. Data analysis was done using STATA version 9. Proportions were compared by chisq test. Logistic regression analysis was used to compare malaria clinical signs and symptoms with blood smear results in patients admitted for severe malaria. $\mathrm{P}$-value $<0.05$ was considered significant.

\section{Results}

\section{Patient characteristics and malaria}

A total of 494 patients were clinically diagnosed and admitted as cases of severe malaria during the one year period. Males accounted for $61.5 \%$ (304) of the patients. Among the patients admitted to IPD, children aged 1-4 years were majority (34.4\%), while children in the age group 5-9 years were the least (13.6\%), Table 1. Most of the patients $77.5 \%$ (383) came from within the urban settings of Tanga city. A total of 245 (49.2\%) patients from both rural and urban settings reported to have taken Sulphadoxine/pyrimethamine or Amodiaquine prior to admission (Table 1).

Overall, 57.7\% (285) of the cases had positive blood smears for malaria parasites. Plasmodium falciparum and P. malariae were the only malaria parasites species detected. $P$. malariae was only found as mixed infection and it accounted for 6.7\% (19) of all infections. Highest smear positive rate was recorded in children under the age of 5 years and thereafter, the prevalence showed a sharp drop that levelled off after the age of 10 years (Table 1).

The highest parasite density of 10734 asexual parasites/ $\mu \mathrm{L}$ (95\% CI: 3912 - 33307) was recorded in patients aged 10-19 years whilst the lowest parasite density (2158 asexual parasites/ $\mu \mathrm{L}, 95 \%$ CI: 956 - 5363) was seen in adults aged $\geq 20$ years, (Table 1 ).

\section{Fever and malaria parasites}

About $70 \%$ of the patients admitted with a diagnosis of severe malaria had fever (axillary temperature $\geq 37.5^{\circ} \mathrm{C}$ ). The highest rate of fever was recorded in children aged $1-4$ years followed by infants and adults aged $\geq 20$ years. Figure 1 shows results of fever in association with blood smears. Children in age group 1-4 years had the highest fever prevalence in association with blood smear (BS) positive for malaria parasites (Figure 1). Adults aged $\geq 20$ years had a high proportion of negative BS with no fever whereas children aged 5-9 years had the lowest rate of both fever and malaria parasites.

\section{Anaemia}

Anaemia was a prominent feature among the patients, with an overall rate of $69.8 \%$ (345). Only 30.2\% (149/494) of the patients had normal $\mathrm{Hb}$ levels $(\mathrm{Hb}>11 \mathrm{~g} / \mathrm{dL})$. Majority (55.2\%) of the cases had mild/moderate anaemia. Severe anaemia was recorded in $14.6 \%$ (72) of the patients and a significant proportion of them $(84.7 \%, p=0.001)$ had positive BS for malaria parasites. The prevalence of severe anaemia was highest in children under the age of 5 years and decreased with increasing age.

\section{Severe malaria manifestations}

Following clinical reassessment of patients in the ward, the proportion of patients with a clinical confirmed diagnosis of severe malaria was 74.7\% (369), (Table 2). Out of 369 cases, a significant proportion (61.5\%) had positive $\mathrm{BS}$ for malaria parasites $(p=0.003)$. Most of these patients were children below the age of 5 years. Assessment by the Blantyre coma scale revealed that 129 out of total 273 under-fives (47.3\%) admitted had 
Table 1 Demographic characteristics of patients initially admitted with a diagnosis of severe malaria

\begin{tabular}{|c|c|c|c|c|c|c|}
\hline \multirow[b]{2}{*}{ Variable } & \multirow[b]{2}{*}{ Overall } & \multicolumn{5}{|c|}{ Age groups } \\
\hline & & Infants & $1-4$ years & 5-9 years & $10-19$ years & $20+$ years \\
\hline Number enrolled & 494 & 103 & 170 & 36 & 67 & 118 \\
\hline Sex ratio (M/F) & $1.6: 1$ & 2:01 & $1: 01$ & 1:02 & $3.5: 1$ & 2.4:1 \\
\hline Mean age (Years, SD) & 12.2 & 0.6 & 2.5 & 6.9 & 15.2 & 36.1 \\
\hline Mean axillary temp $\left({ }^{\circ} \mathrm{C}\right)$ [Range] & $38.5(36.0-41.2)$ & $38.4(36.5-40.6)$ & $38.5(36.0-41.2)$ & $38.3(36.3-40.5)$ & $38.2(36.0-41.0)$ & $38.2(36.0-40.5)$ \\
\hline Malaria parasite density (GMPD)/ $\mu \mathrm{L}$ & 5420 & 5082 & 6397 & 2728 & 10734 & 2158 \\
\hline $\mathrm{GMPD}^{+\dagger}(95 \% \mathrm{Cl})$ & $(2472-13981)$ & (2583-10599) & $(4027-10428)$ & $(880-10207)$ & (3912-33307) & $(956-5363)$ \\
\hline Mean $\mathrm{Hb}$ (g/dl, range) & $8.9(1.6-17.6)$ & $7.7(2.2-15.4)$ & $7.4(1.6-15.6)$ & $9.1(4.0-14.3)$ & $11.4(4.3-17.6)$ & $10.8(2.9-16.9)$ \\
\hline Malaria parasite prevalence (\%) & 57.7 & $58(20.3)$ & $121(42.5)$ & $27(9.5)$ & $39(13.7)$ & $40(14.0)$ \\
\hline Fever (axillary temp $\geq 37.5^{\circ} \mathrm{C}$ ) $\%$ & $348(70.5)$ & $78(22.4)$ & $130(37.4)$ & $26(7.5)$ & $40(11.5)$ & $74(21.2)$ \\
\hline Severe anaemia* (\%) & $72(14.6)$ & $21(29.2)$ & $37(51.4)$ & $3(4.2)$ & $5(6.9)$ & $6(8.3)$ \\
\hline Mild/moderate anaemiat (\%) & $273(55.3)$ & $64(23.4)$ & $114(41.8)$ & $24(8.8)$ & $24(8.8)$ & $47(17.2)$ \\
\hline Splenomegaly prevalence (\%) & $145(29.3)$ & $39(26.9)$ & $62(42.8)$ & $9(6.2)$ & $18(12.4)$ & $17(11.7)$ \\
\hline
\end{tabular}

* Severe anaemia $(\mathrm{Hb}<5 \mathrm{~g} / \mathrm{dL})$

† Mild/moderate anaemia $(\mathrm{Hb}>5 \mathrm{~g} / \mathrm{dl}-\mathrm{Hb}<11 \mathrm{~g} / \mathrm{dL})$

${ }^{{ }^{+\dagger}}$ GMPD $=$ Geometric mean parasite density among observed positive cases only.

signs and symptoms indicative of cerebral malaria but only 89 of the 129 children (69.0\%) had positive BS for malaria parasites (Table 2).

Hyperpyrexia, hyperparasitaemia, hypoglycaemia, convulsions and jaundice were among the accompanying clinical complications of severe malaria observed across all age groups. Among all these complications, hyperpyrexia appeared to be relatively high (19.6\%) (Table 2). Again, the proportion of patients having any of these conditions with malaria parasitaemia was not significant. Fever was identified in $70.5 \%$ (348) of cases but the proportion of those with positive BS for malaria parasites was significantly higher $(p=0.006)$ only in infants (Table $2 \& 3)$. Hyperpyrexia was most prominent in those with positive BS with the exception of infants and the adult age groups who showed comparatively higher proportions of hyperpyrexia

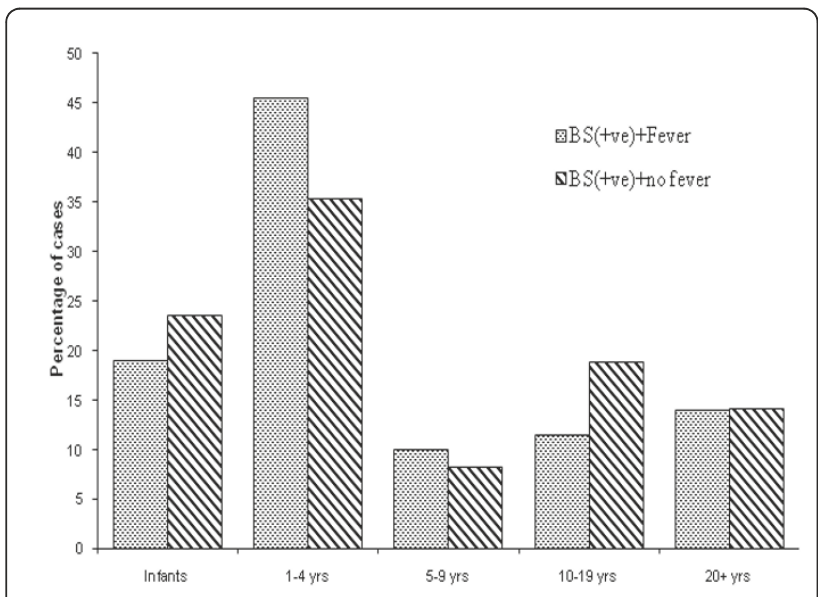

Figure 1 Comparison of blood smear with fever episodes in cases admitted for severe malaria by age groups in those with negative BS. Hypoglycaemia was not a major clinical problem as it was seen only in 5 out of the 494 (1\%) patients of whom only one had positive BS for malaria parasites. Only 4 out of the $494(0.8 \%)$ patients recruited had hyperparasitaemia, and all of them were children under the age of five years. There was a significantly higher proportion (85.5\%) of children aged 1-4 with both malaria and enlarged spleen $(p=0.001)$ as shown in Table 3.

\section{Duration of illness}

The majority of patients in the study had been sick for varying lengths before admission, ranging from 1 to 90 days. The longest period of sickness was documented in adults of 20 years and above who had a median duration of sickness of 7 [IQ range: 4-33] days. On the other hand, a high proportion of the adults aged 20 years and above gave a history of being sick for durations exceeding 2 weeks (Table 4). Generally, the proportion of days of illness seemed to increase with advancing age. Majority of the patients who had positive BS for malaria parasites on admission claimed to have been sick for periods not exceeding one week except a few in the age group of 1-4 years, 10-19 years and adults of 20 years and above. Patients who were admitted with negative BS for malaria parasites reported the longest periods of sickness, the mean duration increasing progressively from 5.6 [95\% CI 4.2 - 7.0] days in infants to 21.8 [95\% CI 15 -28.2] days in adults aged 20 years and above (Table 4).

\section{Deaths}

Most of the patients (95.8\%) were successfully treated and discharged. However, 5 (1.0\%) were transferred to other health facilities for various reasons and 16 (3.2\%) 
Table 2 Comparison of malaria clinical signs and symptoms with blood smear results in patients admitted for severe malaria at Bombo hospital, Tanga, Tanzania

\begin{tabular}{|c|c|c|c|c|c|c|}
\hline \multirow[b]{2}{*}{ Signs \& symptoms } & \multicolumn{2}{|c|}{ Clinical observation alone } & \multirow[b]{2}{*}{ No. +ve (n,\%) } & \multirow[b]{2}{*}{ Odds ratio } & \multirow[b]{2}{*}{$P$-value } & \multirow[b]{2}{*}{$95 \% \mathrm{Cl}$} \\
\hline & Initial total cases**+ & Reassessed cases $(n, \%)^{* *}+$ & & & & \\
\hline Clinical manifestations* & 494 & $369(74.7)$ & $227(61.5)$ & 1.63 & 0.008 & $1.136-2.350$ \\
\hline Cerebral malaria** & 273 & $129(47.3)$ & $89(69.0)$ & 1.34 & 0.26 & $0.807-2.208$ \\
\hline Severe anaemia & 494 & $72(14.6)$ & $61(84.7)$ & 4.85 & 0.001 & $2.509-9.578$ \\
\hline Hyperpyrexia† & 494 & $97(19.6)$ & $59(60.8)$ & 1.17 & 0.486 & $0.746-1.849$ \\
\hline Hyperparasitaemiat† & 494 & $285(57.7)$ & $4(1.4)$ & & 0.085 & \\
\hline Convulsions & 494 & $23(4.7)$ & $17(73.9)$ & 2.15 & 0.107 & $0.831-5.540$ \\
\hline Jaundice & 494 & $6(1.2)$ & $3(50.0)$ & 0.73 & 0.701 & $0.146-3.656$ \\
\hline
\end{tabular}

*+Initial total cases are those admitted with diagnosis of severe malaria from OPD.

**+Reassessed cases are those confirmed to have severe malaria by investigators.

${ }^{*}$ Clinical signs and symptoms used as inclusion criteria for severe malaria.

**According to the Blantyre coma score scale.

†Axillary temperature $\geq 39.5^{\circ} \mathrm{C}$.

t+Parasite count $\geq 250,000 / \mu \mathrm{L}$ of blood.

of the 494 patients died during the one year period. Most of the deaths occurred in patients from the urban areas of Tanga city ( $81.2 \%$ vs $18.3 \%)$. Deaths reported were of infants (12.5\%), children aged 1-4 years (43.8\%) and adults (37.5\%) of over 19 years of age, and all of the deceased adults had negative BS for malaria parasites. Only 6 out of these 16 (37.5\%) deaths had positive BS for malaria parasites of whom 2 were infants and 4 were children aged 1-4 years.

\section{Discussion}

According to health facility statistics, malaria in Tanzania is the leading cause of morbidity and mortality. Ministry of Health data from 2003 show that around 30 per cent of all hospital admissions and 15 per cent of all hospital deaths in Tanzania are due to malaria [24]. Results obtained in our study show that just over half of the patients admitted in the 1 year period October 2004 to September 2005 were cases of malaria. A case of malaria requires the presence of parasites in the blood, supported by fever or history of fever. Reyburn [25] recorded almost similar findings in a study aimed at assessing the diagnosis and outcomes in patients admitted with a diagnosis of severe malaria in north-eastern Tanzania. In the case of fever in BS negative, infections other than malaria should be considered as has been documented by Berkley [26] in Kenyan children where various bacterial infections were found to be responsible for the majority of childhood deaths.

An interesting observation was that a considerable proportion of patients with negative blood smear for malaria parasites and without fever was also admitted as severe cases of malaria. The inclusion of afebrile/apyrexic patients and those with BS negative results for malaria parasites as severe malaria shows that malaria is overreported in this health facility using clinical diagnosis as the principal method of diagnosis. This is likely to occur in most Sub-Saharan Africa and is facilitated through the syndromic approach, popularly termed as integrated management of childhood illness (IMCI) strategy [27], which is not a precise way of diagnosing diseases [28,29]. Reyburn [25] had comparable findings where only $46.1 \%$ of the clinically examined patients had positive blood smears.

The high rate of cases with negative BS for malaria parasites found in our study could have been attributed to the inclusion of patients with acute febrile illnesses caused by aetiologies other than malaria. This is similar to what Njama-Meya [30] reported in a prospective cohort study of malaria treatment restricted to laboratory-confirmed cases in Ugandan children in which 32\% of the febrile episodes were found positive for malaria. This means that majority (68\%) of the episodes attended were caused by various other infections.

The proportion of cases with hypoglycaemia in our study was relatively lower than those reported in other areas of Sub-Sahara Africa. For instance, Taylor et al [31] in a study to find out the clinical associations and relationship to quinine dosage of hypoglycaemia in severe malaria in Malawi reported that $20 \%$ of children had hypoglycaemia before treatment. In another study that was conducted along the coastal areas of Kenya, English et al [32] reported almost similar proportion (16\%) of hypoglycaemia in children on admission. So far, we cannot identify the reasons for the lower proportion of hypoglycaemia recorded in patients in our study.

Moreover, the low sensitivity of laboratory techniques used in diagnosing malaria could have played a part in the increase of BS negative results. Microscopy has some technical drawbacks that make it less sensitive than polymerase chain reaction (PCR) technique in the detection of malaria parasites [33]. It has been noted that considerable 
Table 3 Relationship between clinical conditions and presence of malaria parasites by age group

\begin{tabular}{|c|c|c|c|c|c|c|}
\hline \multirow[b]{2}{*}{ Signs/Symptoms } & \multirow[b]{2}{*}{ Status } & \multicolumn{5}{|c|}{ Age group } \\
\hline & & Infants & $1-4 \mathrm{yrs}$ & 5-9 yrs & $10-19$ yrs & $20+y r s$ \\
\hline & No & $3(20.0)$ & $4(33.3)$ & $4(50.0)$ & $21(56.8)$ & $26(49.1)$ \\
\hline \multirow[t]{3}{*}{ Severe clinical manifestations (\%) } & Yes & $12(62.5)$ & $117(74.1)$ & $23(82.1)$ & $18(60.0)$ & $14(21.5)$ \\
\hline & $P$-value & 0.002 & 0.003 & 0.064 & 0.789 & 0.002 \\
\hline & No & $20(80.0)$ & $30(75.0)$ & $7(70.0)$ & $16(59.3)$ & $12(27.3)$ \\
\hline \multirow[t]{3}{*}{ Fever (Temp $\left.\geq 37.5^{\circ}, \%\right)$} & Yes & $38(48.7)$ & $91(70.0)$ & $20(76.9)$ & $23(57.5)$ & $28(37.8)$ \\
\hline & $P$-value & 0.006 & 0.542 & 0.667 & 0.886 & 0.241 \\
\hline & No & $4(58.6)$ & $49(66.2)$ & & & \\
\hline \multirow[t]{3}{*}{ Cerebral malaria* (\%) } & Yes & $17(51.5)$ & $72(75.0)$ & & & \\
\hline & $P$-value & 0.5 & 0.21 & & & \\
\hline & No & $38(46.3)$ & $86(64.7)$ & $25(75.8)$ & $37(59.7)$ & $38(33.9)$ \\
\hline \multirow[t]{3}{*}{ Severe anaemia ( $\mathrm{Hb}<5 \mathrm{~g} / \mathrm{dl}$, \%) } & Yes & $20(95.2)$ & $35(94.6)$ & $2(66.7)$ & $2(40.0)$ & $2(33.3)$ \\
\hline & $P$-value & 0.0001 & 0.0001 & 0.728 & 0.391 & 0.976 \\
\hline & No & $53(55.8)$ & $112(72.3)$ & $27(75.0)$ & $37(56.9)$ & $38(33.0)$ \\
\hline \multirow[t]{3}{*}{ Convulsions (\%) } & Yes & $4(66.7)$ & $9(69.2)$ & 0 & $2(100)$ & $2(100)$ \\
\hline & $P$-value & 0.602 & 0.815 & & 0.224 & 0.048 \\
\hline & No & $28(43.8)$ & $68(63.0)$ & $20(74.1)$ & $31(63.3)$ & $35(34.7)$ \\
\hline \multirow[t]{2}{*}{ Splenomegaly prevalence (\%) } & Yes & $30(76.9)$ & $53(85.5)$ & $7(77.8)$ & $8(44.4)$ & $5(29.4)$ \\
\hline & P-value & 0.001 & 0.002 & 0.824 & 0.166 & 0.673 \\
\hline
\end{tabular}

${ }^{*}$ Assessed by the Blantyre coma score scale.

number of parasites are lost during the staining process [34-36], leading to either incorrect estimates of parasite density or the smear being considered as negative in the case of scanty or low parasitaemia, usually in densities of $<$ 50 parasites $/ \mu \mathrm{L}$ of blood $[37,38]$. Otherwise these children had infections in other body systems causing illnesses resembling severe malaria, e.g. septicaemia, pneumonia, urinary tract infection, HIV/AIDS and other viral infections.

According to the scores obtained with the Blantyre coma scale, it seems that cerebral malaria is a common manifestation of severe malaria among the under-fives in this area. It was observed that among the sick children assessed, $47.3 \%$ had altered consciousness indicative of cerebral involvement, and about one third of these had negative BS for malaria parasites. Considering the fact that a case definition of malaria requires the presence of asexual parasites in the blood[39,40], it is most likely that the patients who had no parasitaemia could have other infections with cerebral manifestations mimicking cerebral malaria, like cerebrospinal meningitis [41]. The proportion of patients who had cerebral malaria (47.3\%) was actually higher than that recorded by Pankoui Mfonkeu (20.2\%) in Douala, Cameroon [42].

The considerable proportion of patients observed with signs and symptoms of severe malaria, and others presenting with hyperpyrexia (body temperature $\geq 39.5^{\circ} \mathrm{C}$ ) but having no parasitaemia indicates very serious

Table 4 Comparison of duration of illness with blood smear results for malaria parasites

\begin{tabular}{|c|c|c|c|c|c|c|}
\hline \multirow{2}{*}{$\begin{array}{l}\text { Variable } \\
\text { Duration of illness (days) with BS positive }\end{array}$} & \multicolumn{6}{|c|}{ Age group } \\
\hline & Infants & $1-4$ years & $5-9$ years & $10-19$ years & $20+$ years & Total \\
\hline & (\%) & (\%) & (\%) & (\%) & (\%) & \\
\hline$\leq 7$ days & $53(20.6)$ & $109(42.4)$ & $24(9.3)$ & 35 (13.6) & $36(14.0)$ & 257 \\
\hline 8-14 days & $5(25.0)$ & $8(40.0)$ & $3(15.0)$ & $1(5.0)$ & $3(15.0)$ & 20 \\
\hline $15+$ days & 0 & $4(50.0)$ & 0 & $3(37.5)$ & $1(12.5)$ & 8 \\
\hline Median duration (days) of illness [IQ range] & $4[3-6]$ & $4[3,6]$ & $6[3,6]$ & $4[3-6]$ & $4[3-6]$ & \\
\hline \multirow[t]{2}{*}{ Duration of illness (days) with BS negative } & Infants & $1-4$ years & $5-9$ years & $10-19$ years & $20+$ years & Total \\
\hline & (\%) & (\%) & (\%) & $(\%)$ & (\%) & \\
\hline$\leq 7$ days & $39(25.2)$ & $42(27.1)$ & $7(4.5)$ & $25(16.1)$ & $42(27.1)$ & 155 \\
\hline 8-14 days & $5(22.7)$ & $5(22.7)$ & $2(9.1)$ & $1(4.6)$ & $9(40.9)$ & 22 \\
\hline $15+$ days & $1(3.0)$ & $2(6.3)$ & 0 & $2(6.3)$ & $27(84.4)$ & 33 \\
\hline Median duration (days) of illness [IQ range] & $4[3-7.0]$ & $4[3-7]$ & $5[5-7]$ & $4.5[3-7]$ & 7 [4-33] & \\
\hline
\end{tabular}


diagnostic errors and case management problems in our hospitals. In this study, for instance, $38.5 \%$ of patients who presented with severe clinical signs and symptoms of disease pertaining to severe malaria and $19.6 \%$ of patients who had hyperpyrexia had no parasitaemia. This in part is due to inadequate quality of care resulting from dependence on under-trained personnel for most of the clinical work in most of our health facilities, and absence of or insufficient laboratory diagnostic services, particularly in the primary health care units (Mangesho et al. in preparation). Unfortunately undertrained personnel are normally the first to be consulted even in most regional hospitals in Tanzania. It is true that malaria is the leading cause of hospital attendances and hospital admissions in Tanzania so far and probably in sub-Saharan Africa as a whole. But the findings of this study portray doubt on the reliability of the accuracy of data from health facilities.

Furthermore, severe anaemia also appeared to be a problem that was significantly associated with malaria $(\mathrm{p}=$ 0.001). The trend showed that where there was an increase in the proportion of BS positive results for malaria parasites, there was a corresponding increase in the proportion of severe anaemia cases, and vice versa. This phenomenon was more marked in children below the age of five years who also happened to be the group with the highest proportion of BS positive for malaria parasites. In many malaria endemic countries anaemia has been reported to be the most common complication of falciparum malaria and one of the commonest causes of deaths in children $[5,43,44]$. The overall prevalence of malaria-related severe anaemia in our study was $14.6 \%$, which was almost threefold less compared to $46.0 \%$ reported by Newton [45] in children along the coastal area of Kenya between 1989 and 1991 and, by DzeingElla [21] in Gabon between 2000 and 2002, where prevalence of severe anaemia has been reported to be as high as $67 . \%$. In general, the prevalence of malaria-related severe anaemia has a corresponding level with malaria endemicity, for instance, Font [46] found that malaria and anaemia were the main causes of referrals from rural health facilities to the district hospital of Kilombero in Tanzania. Effective malaria control interventions, particularly the country-wide use of insecticide treated bed nets $[47,48]$ might have been responsible for the decline in malaria prevalence recently reported in Tanzania [49], resulting in a parallel decrease in the level of severe anaemia recorded in our study. However, despite the possible association between malaria and anaemia, it is difficult to draw a strong conclusion of malaria being the sole cause and effect of anaemia due to its multi-factorial nature in the tropical environment [50].

It has been noted that patients reported various duration of illness. Some had been sick for periods as short as one day, whereas a number of them were unwell for almost 3 months. Duration of illness documented in adult patients ( $\geq 20$ years) was noted to be significantly long among those with negative BS, indicating that some causes other than malaria, like HIV/AIDS, might have been responsible for the sickness in this age group.

Low death rates might have resulted from good access to health services for the majority of the patients living within the city (as has been evidenced by the fact that half of the patients already received some antimalarials even before coming to hospital). Prompt treatment by hospital staff due in part to over-diagnosis of malaria [25] played a role in the low rate of malaria-specific deaths. The use of quinine has proved to be very effective in reducing mortality in our study although recent report indicates that artesunate performs better [51].

Almost half of the patients enrolled in our study had a history of taking antimalarial drugs prior to admission. These patients most likely got their medicines either from low level health facilities before they were referred or they might have obtained the drugs over the counter, which is a common practice in Tanzania. Some studies conducted in the country show that over $71 \%$ of patients treat themselves even before consulting a health facility $[52,53]$.

\section{Conclusions}

The high proportion of fever cases in patients with BS negative results for malaria parasites poses the question as to what could be the actual cause of illness. There is a need to find out if malaria still continues to be the leading cause of morbidity and mortality in Tanzania and sub-Saharan Africa as is believed to be, particularly bearing in mind the impact of HIV/AIDS. Use of more specific RDT might also help. This would reduce the problem of over-diagnosis of malaria and bring about rational use of antimalarials and other relatively expensive drugs. We need to revisit the usefulness of IMCI in terms of its impact on disease over-diagnosis and over-prescription of drugs. Improvement of clinical and laboratory diagnosis of malaria is crucial for proper case management and reliable data collection in the changing epidemiological setting. Blood and urine culture tests could be an important component of management of febrile illnesses in general and cases of non malaria febrile illness in particular.

\section{Acknowledgements}

The authors would like to thank the Ministry of Health and Social Welfare (MoHSW) Tanzania, for the provision of research funds through the National Institute for Medical Research (NIMR), Head Office. We would also like to thank the administrative body and the management team of Bombo regional hospital of Tanga led by Dr Margaret Mhando (Medical Superintendent), for allowing us to conduct this study in their hospital. Particular acknowledgement goes to the medical staff and nurses of Galanos wards 3 and 4 (female and male medical wards, respectively), the Paediatric 
wards 12 and 13, including the intensive care unit (ICU) under the supervision of Dr Firmina Mberesero, and grade 1 and 2 wards for their commendable support in the data collection process. We wish to express our sincere gratitude to the patients who participated in this study and, their parents/guardians who heartedly allowed their children to take part in this project.

\section{Authors' contributions}

HAM designed the study, collected data and prepared the manuscript. MLK designed the study, analyzed the data and prepared the manuscript. MML designed the study and prepared the manuscript. BPM and FFT participated in data analysis. SHS, EKM and JAA collected data. All authors read and approved the final manuscript.

\section{Competing interests}

The authors declare that they have no competing interests.

Received: 4 January 2011 Accepted: 29 September 2011 Published: 29 September 2011

\section{References}

1. WHO: The African Malaria Report. 2003

2. ter Kuile FO, Parise ME, Verhoeff FH, Udhayakumar V, Newman RD, van Eijk AM, Rogerson SJ, Steketee RW: The burden of co-infection with human immunodeficiency virus type 1 and malaria in pregnant women in sub-saharan Africa. Am J Trop Med Hyg 2004, 71:41-54.

3. Severe falciparum malaria. World Health Organization, Communicable Diseases Cluster. Trans R Soc Trop Med Hyg 2000, 94(Suppl 1):S1-90.

4. Slutsker L, Taylor TE, Wirima JJ, Steketee RW: In-hospital morbidity and mortality due to malaria-associated severe anaemia in two areas of Malawi with different patterns of malaria infection. Trans $R$ Soc Trop Med Hyg 1994, 88:548-551.

5. Menendez C, Fleming AF, Alonso PL: Malaria-related anaemia. Parasitol Today 2000, 16:469-476.

6. Kitua AY, Smith TA, Alonso PL, Urassa H, Masanja H, Kimario J, Tanner M: The role of low level Plasmodium falciparum parasitaemia in anaemia among infants living in an area of intense and perennial transmission. Trop Med Int Health 1997, 2:325-333.

7. Granja AC, Machungo F, Gomes A, Bergstrom S, Brabin B: Malaria-related maternal mortality in urban Mozambique. Ann Trop Med Parasitol 1998, 92:257-263.

8. Marsh K, Forster D, Waruiru C, Mwangi I, Winstanley M, Marsh V, Newton C, Winstanley P, Warn P, Peshu N, et al: Indicators of life-threatening malaria in African children. N Engl J Med 1995, 332:1399-1404.

9. The United Republic of Tanzania, Prime Minister's Office: Regional Administration and Local Government: Annual Report Bombo HospitalTanga. 2000.

10. Bodker R, Akida J, Shayo D, Kisinza W, Msangeni HA, Pedersen EM, Lindsay SW: Relationship between altitude and intensity of malaria transmission in the Usambara Mountains, Tanzania. J Med Entomol 2003, 40:706-717.

11. Mmbando BP, Segeja MD, Msangeni HA, Sembuche SH, Ishengoma DS, Seth MD, Francis F, Rutta AS, Kamugisha ML, Lemnge MM: Epidemiology of malaria in an area prepared for clinical trials in Korogwe, northeastern Tanzania. Malar J 2009, 8:165.

12. Ceesay SJ, Casals-Pascual C, Nwakanma DC, Walther M, Gomez-Escobar N, Fulford AJ, Takem EN, Nogaro S, Bojang KA, Corrah T, et al: Continued decline of malaria in The Gambia with implications for elimination. PLOS One 5:e12242.

13. Gething PW, Smith DL, Patil AP, Tatem AJ, Snow RW, Hay SI: Climate change and the global malaria recession. Nature 465:342-345.

14. Okiro EA, Hay SI, Gikandi PW, Sharif SK, Noor AM, Peshu N, Marsh K, Snow RW: The decline in paediatric malaria admissions on the coast of Kenya. Malar J 2007, 6:151

15. Kamugisha ML, Msangeni H, Beale E, Malecela EK, Akida J, Ishengoma DR, Lemnge MM: Paracheck Pf compared with microscopy for diagnosis of Plasmodium falciparum malaria among children in Tanga City, northeastern Tanzania. Tanzan J Health Res 2008, 10:14-19.

16. Molyneux ME, Taylor TE, Wirima JJ, Borgstein A: Clinical features and prognostic indicators in paediatric cerebral malaria: a study of 131 comatose Malawian children. Q J Med 1989, 71:441-459.
17. Waller D, Krishna S, Crawley J, Miller K, Nosten F, Chapman D, ter Kuile FO, Craddock C, Berry C, Holloway PA, et al: Clinical features and outcome of severe malaria in Gambian children. Clin Infect Dis 1995, 21:577-587.

18. World Health Organisation: Manegement of severe malaria-A practical handbook 2rd edition Geneva: WHO; 2000.

19. Tomashek KM, Woodruff BA, Gotway CA, Bloland P, Mbaruku G: Randomized intervention study comparing several regimens for the treatment of moderate anemia among refugee children in Kigoma Region, Tanzania. Am J Trop Med Hyg 2001, 64:164-171.

20. Odhiambo FO, Hamel MJ, Williamson J, Lindblade K, ter Kuile FO, Peterson E, Otieno P, Kariuki S, Vulule J, Slutsker L, Newman RD: Intermittent preventive treatment in infants for the prevention of malaria in rural Western kenya: a randomized, double-blind placebocontrolled trial. PLoS One 5:e10016.

21. Dzeing-Ella A, Nze Obiang PC, Tchoua R, Planche T, Mboza B, Mbounja M, Muller-Roemer U, Jarvis J, Kendjo E, Ngou-Milama E, et al: Severe falciparum malaria in Gabonese children: clinical and laboratory features. Malar J 2005, 4:1.

22. Idro R: Severe anaemia in childhood cerebral malaria is associated with profound coma. Afr Health Sci 2003, 3:15-18.

23. Mockenhaupt FP, Ehrhardt S, Burkhardt J, Bosomtwe SY, Laryea S, Anemana SD, Otchwemah RN, Cramer JP, Dietz E, Gellert S, Bienzle U: Manifestation and outcome of severe malaria in children in northern Ghana. Am J Trop Med Hyg 2004, 71:167-172.

24. Ministry of Health: Health Abstracts. Dar es salaam, United Republic of Tanzania: Ministry of Health; 2003.

25. Reyburn H, Mbatia R, Drakeley C, Carneiro I, Mwakasungula E, Mwerinde O, Saganda K, Shao J, Kitua A, Olomi R, et al: Overdiagnosis of malaria in patients with severe febrile illness in Tanzania: a prospective study. BMJ 2004, 329:1212.

26. Berkley JA, Lowe BS, Mwangi I, Williams T, Bauni E, Mwarumba S, Ngetsa C, Slack MP, Njenga S, Hart CA, et al: Bacteremia among children admitted to a rural hospital in Kenya. N Engl J Med 2005, 352:39-47.

27. Font F, Alonso Gonzalez M, Nathan R, Kimario J, Lwilla F, Ascaso C, Tanner M, Menendez C, Alonso PL: Diagnostic accuracy and case management of clinical malaria in the primary health services of a rural area in south-eastern Tanzania. Trop Med Int Health 2001, 6:423-428.

28. Adehor $A B$, Burrell PR: The Integrated Management of Health Care Strategies and Differential Diagnosis by Expert System Technology: A Single-Dimensional Approach. 2008 [http://www.waset.org/journals/waset/ v44-91.pdf].

29. Rowe AK, Hirnschall G, Lambrechts T, Bryce J: Linking the integrated management of childhood illness (IMCI) and health information system (HIS) classifications: issues and options. Bull World Health Organ 1999, 77:988-995.

30. Njama-Meya D, Clark TD, Nzarubara B, Staedke S, Kamya MR, Dorsey G: Treatment of malaria restricted to laboratory-confirmed cases: a prospective cohort study in Ugandan children. Malar J 2007, 6:7.

31. Taylor TE, Molyneux ME, Wirima JJ, Fletcher KA, Morris K: Blood glucose levels in Malawian children before and during the administration of intravenous quinine for severe falciparum malaria. N Engl J Med 1988, 319:1040-1047.

32. English M, Wale S, Binns G, Mwangi I, Saurewein H, Marsh K: Hypoglycaemia on and after admission in Kenyan children with severe malaria. Q J Med 1998, 91:191-197.

33. Coleman RE, Sattabongkot J, Promstaporm S, Maneechai N, Tippayachai B, Kengluecha A, Rachapaew N, Zollner G, Miller RS, Vaughan JA, et al: Comparison of PCR and microscopy for detection of asymptomatic malaria in a Plasmoium falciparum/vivax endemic area in Thailand. Malar J 2006, 5.

34. Shute PG: The staining of malaria parasites. Trans $R$ Soc Trop Med Hyg 1966, 60:412-416.

35. Bejon P, Andrews L, Hunt-Cooke A, Sanderson F, Gilbert SC, Hill AV: Thick blood film examination for Plasmodium falciparum malaria has reduced sensitivity and underestimates parasite density. Malar J 2006, 5:104.

36. Dowling MA, Shute GT: A comparative study of thick and thin blood films in the diagnosis of scanty malaria parasitaemia. Bull World Health Organ 1966, 34:249-267.

37. Wongsrichanalai C, Barcus MJ, Muth S, Sutamihardja A, Wernsdorfer WH: A review of malaria diagnostic tools: microscopy and rapid diagnostic test (RDT). Am J Trop Med Hyg 2007, 77:119-127. 
38. Tangpukdee N, Duangdee C, Wilairatana P, Krudsood S: Malaria diagnosis: a brief review. Korean J Parasitol 2009, 47:93-102.

39. Redd SC, Bloland PB, Kazembe PN, Patrick E, Tembenu R, Campbell CC: Usefulness of clinical case-definitions in guiding therapy for African children with malaria or pneumonia. Lancet 1992, 340:1140-1143.

40. Rogers WO, Atuguba F, Oduro AR, Hodgson A, Koram KA: Clinical case definitions and malaria vaccine efficacy. J Infect Dis 2006, 193:467-473.

41. Wright PW, Avery WG, Ardill WD, McLarty JW: Initial clinical assessment of the comatose patient: cerebral malaria vs. meningitis. Pediatr Infect Dis J 1993, 12:37-41.

42. Mfonkeu JB, Gouado I, Kuate HF, Zambou O, Grau G, Combes V, Zollo PH: Clinical presentation, haematological indices and management of children with severe and uncomplicated malaria in Douala, Cameroon. Pak J Biol Sci 2008, 11:2401-2406.

43. Rogerson S: What is the relationship between haptoglobin, malaria, and anaemia? PLoS Med 2006, 3:e200

44. Ronald LA, Kenny SL, Klinkenberg E, Akoto AO, Boakye I, Barnish G, Donnelly MJ: Malaria and anaemia among children in two communities of Kumasi, Ghana: a cross-sectional survey. Malar J 2006, 5:105.

45. Newton CR, Warn PA, Winstanley PA, Peshu N, Snow RW, Pasvol G, Marsh K: Severe anaemia in children living in a malaria endemic area of Kenya. Trop Med Int Health 1997, 2:165-178.

46. Font F, Quinto L, Masanja H, Nathan R, Ascaso C, Menendez C, Tanner M, Schellenberg J, Alonso P: Paediatric referrals in rural Tanzania: the Kilombero District Study - a case series. BMC Int Health Hum Rights 2002, $2: 4$

47. Bernard J, Mtove G, Mandike R, Mtei F, Maxwell C, Reyburn H: Equity and coverage of insecticide-treated bed nets in an area of intense transmission of Plasmodium falciparum in Tanzania. Malar J 2009, 8:65.

48. Hanson K, Marchant T, Nathan R, Mponda H, Jones C, Bruce J, Mshinda H, Schellenberg JA: Household ownership and use of insecticide treated nets among target groups after implementation of a national voucher programme in the United Republic of Tanzania: plausibility study using three annual cross sectional household surveys. BMJ 2009, 339:b2434.

49. Mmbando BP, Vestergaard LS, Kitua AY, Lemnge MM, Theander TG, Lusingu JP: A progressive declining in the burden of malaria in northeastern Tanzania. Malar J 9:216.

50. Crawley J: Reducing the burden of anemia in infants and young children in malaria-endemic countries of Africa: from evidence to action. Am Trop Med Hyg 2004, 71:25-34.

51. Dondorp AM, Fanello Cl, Hendriksen IC, Gomes E, Seni A, Chhaganlal KD, Bojang K, Olaosebikan R, Anunobi N, Maitland K, et al: Artesunate versus quinine in the treatment of severe falciparum malaria in African children (AQUAMAT): an open-label, randomised trial. Lancet 2010, 376:1647-1657.

52. Nsimba SE, Rimoy GH: Self-medication with chloroquine in a rural district of Tanzania: a therapeutic challenge for any future malaria treatment policy change in the country. J Clin Pharm Ther 2005, 30:515-519.

53. Mnyika KS, Killewo JZ, Kabalimu TK: Self-medication with antimalarial drugs in Dar es Salaam, Tanzania. Trop Geogr Med 1995, 47:32-34.

\section{Pre-publication history}

The pre-publication history for this paper can be accessed here: http://www.biomedcentral.com/1471-2334/11/256/prepub

\section{doi:10.1186/1471-2334-11-256}

Cite this article as: Msangeni et al.: Prospective study on severe malaria among in-patients at Bombo regional hospital, Tanga, north-eastern Tanzania. BMC Infectious Diseases 2011 11:256.

\section{Submit your next manuscript to BioMed Central and take full advantage of:}

- Convenient online submission

- Thorough peer review

- No space constraints or color figure charges

- Immediate publication on acceptance

- Inclusion in PubMed, CAS, Scopus and Google Scholar

- Research which is freely available for redistribution

Submit your manuscript at www.biomedcentral.com/submit
Biomed Central 